\title{
WIRELESS POWER TRANSFER USING INDUCTIVE COUPLING PRINCIPLE FOR PORTABLE CHARGING DEVICES THROUGH SOLAR PHOTOVOLTAIC WITH AUTO SWITCHING
}

\author{
Suman Kumar Laha ${ }^{*}$, Pradip Kumar Sadhu ${ }^{1}$, Ankur Ganguly ${ }^{2}$ and \\ Ashok Kumar Naskar ${ }^{2}$ \\ ${ }^{1}$ Department of Electrical Engineering, Indian Institute of Technology (Indian \\ School of Mines), Dhanbad, Jharkhand-826004, India \\ ${ }^{2}$ Department of Electrical Engineering, Techno International Batanagar, \\ Kolkata-700141, India \\ *sumanlaha88@gmail.com
}

\begin{abstract}
This paper is an integration of wireless power transfer of solar PV cell to a wirelessly connected load for attaining high power transmission efficiency. The objective is to find out a control technique which will decrease the total cost of the system and maximize the system efficiency at the same time. The power supply has been taken primarily from a solar PV. The power will be switched to battery mode automatically in the absence of effective solar energy. An equivalent circuit model is portrayed with a transreceiver for power transmission. The inductive coils here will help as an antenna receiver and the rectifier are used to convert AC to DC. A low voltage DC load is driven by the receiver circuit. In order to increase the load, the frequency and the input power should be higher. This research will be applicable for any kind of wireless power charger which is generally used in electric vehicles and electronic gadgets in day to day life.
\end{abstract}

Keywords- Photovoltaic system, Inductive Power Transfer, Topological compensation, Switching circuit, Portable devices

\section{INTRODUCTION}

In recent times it has been noticed that a major development in the field of wireless power transfer has been executed to eliminate the use of cables. Imagine that we are sitting in the house, office or car, placing the electronic gadgets on the table or any other places and the electronic gadgets lights up and starts charging automatically without any kind of connectors or cables. By the improvement of electronic devices the importance of electric power transfer has been emphasized since most of the electronic devices still need the wired power connection to use the electric power. This leads to several physical inconveniences by power cables. To escape from this field, the concept of wireless power transfer was introduced $[1,2]$. With the advanced technology of wireless power transfer, the cost of connectors can be reduced and it can also be helpful to charge the electronic devices where the electronic devices can be fully enclosed to avoid corrosion. It will be useful to deliver the power for rotating and highly mobile industrial equipped systems in wet as well as dry environments. Wireless power transfer can be defined as the

Received: June 4, 2019

Reviewed: August 12, 2019

Accepted: September 5, 2019

* Corresponding Author

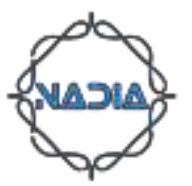


transmission of electrical energy from a power source to an electrical load through the air without interconnecting conductors. This concept was first introduced by Nicola Tesla. He tried to develop a wireless system to transfer huge power over a long distance. It can offer the possibility of connector free environment with improvement of both size and reliability for electronic devices [3]. Wireless power transfer techniques can be rightly categorized by ranges like near field and far field. In the near field, the propagation of electromagnetic waves is used. One of the drawbacks for the far-field approaches is the trade-off between directivity and transmission efficiency. In the near field inductive coupling is mostly recommended. It is not the propagation of electromagnetic waves but the transmission at a distance less than wavelength. This technique has very good transmission efficiency within a few centimeters. However the efficiency at the distance over than a few centimeters is rapidly decreased as the receiver coil is moved away from the transmitter coil. Looking at the scenario that, as the supply of general source of energy like coal, natural gas, oil are getting lower and lower day by day but the demand of power in industry as well as domestic area are increasing rapidly in the field of wireless power transfer. So as an alternative to meet the futuristic demand, renewable energy sources can be the absolute alternative as its supply is plentiful and it is cheap also. But the power which we are getting from solar is not constant always .It keeps on changing and the voltage level which we are obtaining from it, is also very small. Therefore it is not easy and reliable to connect the loads directly to it [4]-[7].

This paper focuses on inductive power transfer which transfers power magnetically from primary windings to secondary windings with the help of specially constructed inductor. In this paper a hardware structure has been developed for charging the low power consumable portable device with the help of wireless transmission of solar power. The system has been designed in three segments. First through transreceiver, electromagnetic power transferred via inductive coils to receiver units. Secondly through inductive coupling mechanism which behaves as an antenna, the signal transferred to the receiver side. Thereafter the signal forwarded to the bridge rectifier which acts to convert the AC voltage to DC voltage. Finally the rectifier supplies DC voltage to the load .The overall system design and hardware operation of the proposed system is carried out and tested in room temperature.

The paper is organized in the following manner. First the discussion goes on with the statistical survey analysis in Section 2, followed by principle of wireless power transmission in Section 3. Then the block diagram and methodology of the proposed work is discussed in Section 4. The result with discussion and conclusion are portrayed in Section 5 and Section 6 respectively.

\section{STATISTICAL SURVEY ANALYSIS}

Since many years researchers are trying to transfer the power in wireless mode, several ways have been adopted by the researchers in this field. M Fareq et al., showed a good approach for transferring the power in wireless mode using solar power as a source for mobile phone charging. In their article based on the experimental results they have shown that for efficient wireless power transfer using inductive coupling principle, has several aspects in terms of distance, frequency etc. Their results shows that nearer the distance, voltage transfer will become higher and higher. Additionally wireless power transfer is not much affected by shielding materials such as the presence of hands, books, plastics etc., [8]. T Rohith et al., demonstrated a different line for transferring the solar power using inductive resonant principle. In their manuscript they have demonstrated a comparison between inductive resonance principle and inductive coupling principle. They have found out that, efficient transmission of power at lower frequencies can be achieved using resonance principle with high Q factor [9]. A Salman et al., represented an efficient wireless electric power transfer using magnetic resonance coupling where they have 
shown how efficiently one can transfer the electric power wirelessly through magnetic resonance coupling principle[10]. X Liu et al., proposed an optimal operation of contact less transformers with resonance in secondary circuits where the authors reveals that contactless transformers is a key element for inductive power transfer system. For developing the efficiency level of this system the authors used a resonant tank circuit by adding a supplementary capacitor in series-series or in parallel series fashion in the secondary windings side [11]. D Ahn et al., reveals a study on magnetic field repeater about wireless power transfer where the authors have shown that by introducing the repeaters in between the transmitter and receiver the distance of the wireless power transfer can be significantly increased. By calculating each repeater power, efficiency and output impedance can be found out, keeping in mindthe optimum repeaters position and numbers. The effective approximation of choosing the repeaters position will help a lot to double the coupling efficiency between transmitter and receiver [12].W $\mathrm{Na}$ et al., demonstrated in their article an energy efficient mobile charging device based on wireless power transfer with the use of internet of things (IoT) in a slightly different way. They have formulated a problem to reduce the energy consumption when charging the IoT devices by observing the path of gesture of a mobile charger with efficient charging points [13]. U Baroudi et al., have shown in their paper an automatic robot assisted maintenance of wireless sensor network using wireless energy transfer techniques. In their article, they have portrayed a framework called wirelessly energy charged for battery preservation which includes recharging sensor batteries using mobile robots [14]. L Chen et al., in their paper showed an efficient power management of multiple pickup inductive power transfer system for material handling application where the authors have shown a novel power management control for the use of two common load regulation process called fast switching and slow switching for material handling application. Their line of approach allows power suppliers a smaller capacity to be used without cooperating with the system integrity and system cost [15]. A Caj et al., in their article has demonstrated a $2 \mathrm{~kW}, 95 \%$ efficiency inductive power transfer system using gallium nitride gate injection transistors with a high frequency inverter and a gallium nitride power transistor. Their system has the benefit of low on resistance and gate charge capacity to demolish the switching and conductor loss[16]. J Dai et al., in their work have shown single active switch power electronics for kilowatt scale capacitive power transfer (CPT) where they have shown the development of capacitive power transfer as a contactless power transfer resolution over a short distance. Their work signifies the need of efficient power electronics which is suitable for CPT application in the high power areas keeping the cost economical[17].S.M Dehgan et al., depicted a system of solar charger with LED driver using capacitor less multiport converter. In their article they have shown a three port converter without capacitor in the common bus region. It can be used for a solar charger application. Out of the three ports, two of them are connected to a solar panel. They have used the battery bank and third port as a LED driver with a constant current source. This will be helpful for proposing a special type of switching with a better control and design approaches for the solar charger system [18].

\section{PRINCIPLE OF WIRELESS COMMUNICATION}

When an alternating current powers a copper coil, it produces a short range magnetic field and a voltage is induced in it. Therefore the generated power is being transferred wirelessly. Primary and secondary compensation is an extremely important aspect of wireless power transfer system based on inductive coupling. Fig. 1 shows the basic model of transformer for wireless power transfers where $L_{P}$ and $L_{S}$ are the primary and secondary inductor of the transformer and $\mathrm{M}$ is the mutual inductance between the coils. By dropping the coil resistance or by increasing the mutual inductance the efficiency can be increased between the two coils. It is mainly introduced to improve the efficiency and 
power transfer capability of the inductive couplers. Due to these characteristics the impedance seen by the source in higher operating frequencies becomes more inductive in nature. Inductive power transfer can be categorized mainly by four different topologies. These methods are series-series, series-parallel, parallel-series and parallel-parallel [19, 20].

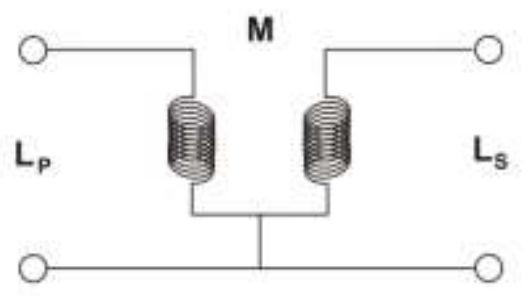

Fig. 1 Basic transformer structure used for WPT

The frequency based characteristics comes in the transformer because of the presence of the two elements $L_{P}$ and $L_{S}$ which is shown in Fig. 1. Thus the current becomes

$$
I=V /(-j w M)
$$

\subsection{SERIES-SERIES COMPENSATION PROCESS}

The first compensation process is series-series combination which is shown in Fig. 2(a). As soon as the frequency $\omega$, applies in the system, the series capacitor $\mathrm{C}_{\mathrm{P}-\mathrm{SS}}$ starts to compensate the inductor $L_{P}$ to make the voltage strong like $V_{S}$. So,

$$
C_{P-S S}=1 /\left(w^{2} L_{P}\right)
$$

Thus, $V=V_{S}$, and the equation (1) becomes

$$
I_{L-S S}=-\frac{1}{j w M} V_{S}
$$

With this, the series capacitor $\mathrm{C}_{\mathrm{S}-\mathrm{SS}}$ compensates $\mathrm{L}_{\mathrm{S}}$ for optimizing the effective power transfer which is coming out of $\mathrm{V}_{\mathrm{S}}$.

$$
\text { So, } C_{s-S S}=1 /\left(w^{2} L_{s}\right)
$$

Therefore, the output voltage is directed by

$$
\frac{V_{L-S S}}{V_{S}}=-\frac{R_{L}}{j w h \sqrt{L_{P} L_{S}}}, \quad h=\frac{M}{\sqrt{L_{P} L_{S}}}
$$

The major problem which arises here is the open circuit condition on the load side which is avoided by doing the short circuit on the load side which restricts not to flow any over current on both source and load side. These overall characteristics can be seen from impedance at the source terminals.

$$
Z_{S L-S S}=\frac{\left(w M^{2}\right)}{R_{L}}
$$

\subsection{SERIES-PARALLEL COMPENSATION PROCESS}

In the second compensation techniques $\mathrm{C}_{\mathrm{P}-\mathrm{SP}}$ is in series with $\mathrm{L}_{\mathrm{P}}$ in the left side of the transformer and $\mathrm{C}_{\mathrm{S}-\mathrm{SP}}$ is present parallel to the load resistance which is shown in Fig.2 (b).

For this topology different capacitor values are 


$$
C_{P-S P}=\frac{1}{\left(w^{2} L_{P}\right)}, C_{S-S P}=\frac{1}{\left(w^{2} L_{S}\right)}
$$

To eliminate the reactive power from the input source the equation (7) becomes

$$
C_{P-S P}=\frac{1}{\left[w^{2} L_{P}\left(1-h^{2}\right)\right]}, \text { where, } h^{2}=\frac{M^{2}}{L_{P} L_{S}}, C_{S-S P}=\frac{1}{\left(w^{2} L_{S}\right)}
$$

This compensation delivers a voltage source performance, where the generated output voltage becomes free from the load.

$$
\frac{V_{L-S P}}{V_{S}}=\frac{1}{w^{2} M C_{S-S P}}=\frac{L_{S}}{M}=\frac{1}{M} \sqrt{\frac{L_{S}}{L_{P}}}
$$

From equation (9) it is revealed that $\mathrm{V}_{\mathrm{L}-\mathrm{SP}}$ and $\mathrm{V}_{\mathrm{S}}$ is in phase. Now in the input side the impedance is

$$
Z_{S L-S P}=\frac{w^{2} M^{2} R_{L} C_{P-S P}}{L_{S}}=\left(\frac{M}{L_{S}}\right)^{2} R_{L}
$$

\subsection{PARALLEL-PARALLEL COMPENSATION PROCESS}

The third compensation topology which is depicted here is parallel-parallel process where on both side of the transformer a parallel connected capacitor has placed with an additional inductor $\mathrm{L}_{\mathrm{i}-\mathrm{P}} \mathrm{P}$ in input side as an interface between $\mathrm{V}_{\mathrm{S}}$ and $\mathrm{C}_{\mathrm{P}-\mathrm{PP}}$ as shown in Fig. 2(c).

The impedance in the input terminal of this V/I converter is

$$
Z_{1}=\frac{-j w M^{2}}{L_{S}}+\frac{w^{2} M^{2} R_{L} C_{S-S P}}{L_{S}}=-j w \frac{M^{2}}{L_{S}}+\left(\frac{M}{L_{S}}\right)^{2} R_{L}
$$

For doing completely compensate the system seen from $V_{S}$, the parallel capacitor should be

$$
\begin{aligned}
& C_{P-P P}=\frac{1}{\left[w^{2} L_{P}\left(1-h^{2}\right)\right]} \\
& \text { And } L_{i-P P}=L_{P}\left(1-h^{2}\right) \\
& \text { Here, } C_{S-P P}=\frac{1}{\left(w^{2} L_{S}\right)}
\end{aligned}
$$

The combination of $\mathrm{L}_{\mathrm{i}-\mathrm{PP}}$ and $\mathrm{C}_{\mathrm{S}-\mathrm{PP}}$ behaves like a current source. Because of this current source the V/I converter will get a constant current and therefore to the load the total system acts like a current source.

So, the output current is

$$
I_{L-P P}=\frac{V_{S} M}{j w L_{P} L_{S}\left(1-h^{2}\right)}=\frac{h^{2}}{1-h^{2}} \times \frac{1}{j w M} V_{S}
$$

The equation demonstrates that $I_{L-P P}$ is shifted by $90^{\circ}$. Due to this current, the output voltage is ruled by

$$
\frac{V_{L-P P}}{V_{S}}=\frac{h}{1-h^{2}} \times \frac{R_{L}}{j w \sqrt{L_{P} L_{S}}}
$$

Equation (16) also represents that $V_{L-P P}$ is shifted by $90^{\circ}$ with $V_{S}$. Because of this shifted nature of current voltage characteristics the impedance seen at the input terminals becomes

$$
Z_{S L-P P}=\frac{\left\{w L_{P} L_{S}\left(1-h^{2}\right)\right\}^{2}}{M^{2} R_{L}}=\frac{(w M)^{2}}{R_{L}}\left(\frac{1}{h^{2}}-1\right)^{2}
$$




\subsection{PARALLEL-SERIES COMPENSATION PROCESS}

The fourth compensation technique which has been applied here is Parallel-Series compensation technique in Fig.2(d) where a capacitor is placed in parallel with the converter input and a capacitor is situated in series with the output and an extra inductor $\mathrm{L}_{\mathrm{i}-\mathrm{PS}}$ has been placed in between $\mathrm{V}_{\mathrm{S}}$ and $\mathrm{C}_{\mathrm{p}-\mathrm{PS}}$.

Now the impedance which is seen at the input terminal of the $\mathrm{V} / \mathrm{I}$ converter is

$$
Z_{2}=\frac{w^{2} M^{2}}{R_{L}}
$$

Now again for being totally compensated at the input side of the converter terminals, the parallel capacitor $\mathrm{C}_{\mathrm{p}-\mathrm{PS}}$ should be

$$
C_{p-P S}=\frac{1}{\left(w^{2} L_{P}\right)}
$$

As a result, the edge inductor will be equal to primary connected inductor of the converter i.e.,

$$
L_{i-P S}=L_{P}
$$

and the series capacitor with the load will be equal to

$$
C_{S-P S}=\frac{1}{w^{2} L_{S}}
$$

Now the overall structure portraits like a voltage source and the output voltage is controlled by

$$
\text { By } \frac{V_{L-P S}}{V_{S}}=w^{2} M C_{p-P S}=\frac{M}{L_{P}}=h \sqrt{\frac{L_{S}}{L_{P}}}
$$

From equation (22) it is exhibited that $\mathrm{V}_{\mathrm{L}-\mathrm{PS}}$ and $\mathrm{V}_{\mathrm{S}}$ are in phase with each other. Therefore the impedance noticed at the input terminal is

$$
Z_{S L-P S}=\left(\frac{L_{P}}{M}\right)^{2} R_{L}
$$

In Table $\mathrm{VI}$, the concise output ac voltages $\mathrm{V}_{\mathrm{L}-\mathrm{SS}}, \mathrm{V}_{\mathrm{L}-\mathrm{SP}}, \mathrm{V}_{\mathrm{L}-\mathrm{PP}}$ and $\mathrm{V}_{\mathrm{L}-\mathrm{PS}}$ with their formulas of the four compensated converter techniques have been represented accordingly.For portable device charging application series-series topology is preferred because this topology can transfer more power independent of the magnetic coupling between the inductors[21]-[24].

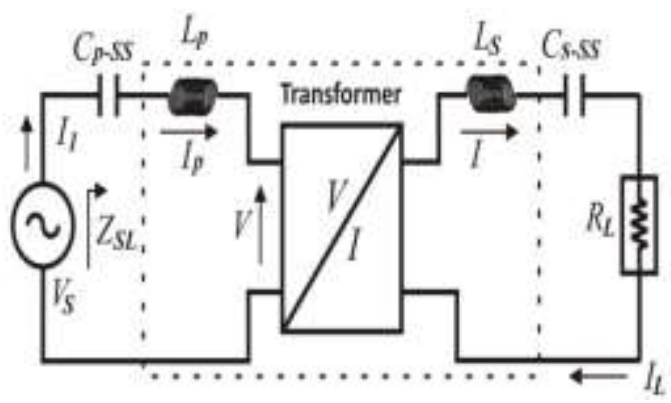

(a)

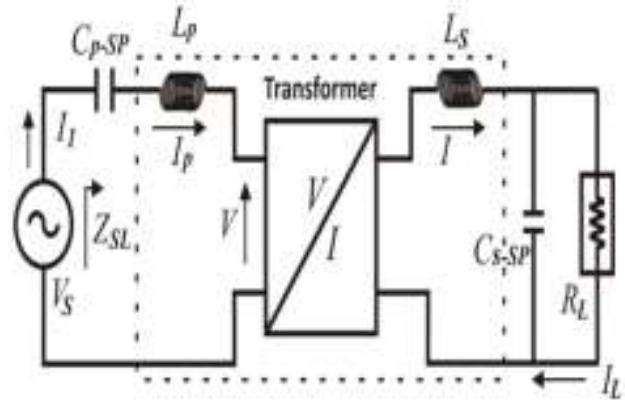

(b) 


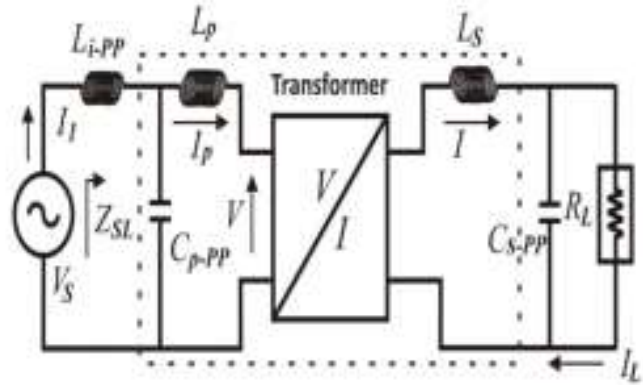

(c)

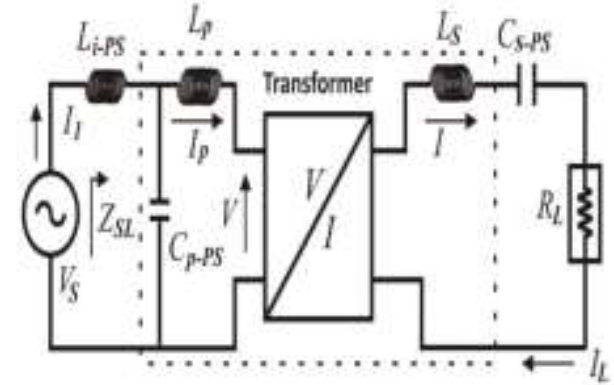

(d)

Fig. 2 (a)Series-Series compensation technique (b) Series-Parallel compensation technique (c) Parallel-Parallel compensation technique (d) Parallel-Series compensation technique

\section{METHODOLOGY OF THE PROPOSED WORK}

In Figure 3 the circuit diagram of the proposed work has been shown where it is revealed that, at first input from solar panel goes to a comparator circuit where the other comparable variable is set by the user. Vcc has taken from battery. Then output of the comparator goes to the base of npn and pnp. When output of the comparator is 1 then npn gets turned on and pnp gets turned off and the battery starts charging itself from the PV cell through voltage regulator and one part of the solar goes to the transmitter as well. At the same moment pnp is off, so the output from the battery doesn't go to anywhere as its output path is switched off. Next when the output of the comparator goes to 0 then pnp gets turned on and npn gets turned off and the charging of battery gets stopped. Therefore the current to the transmitter goes from the battery through pnp. At the receiver side the AC signal which is coming from the transmitter, converted to DC via rectifier.

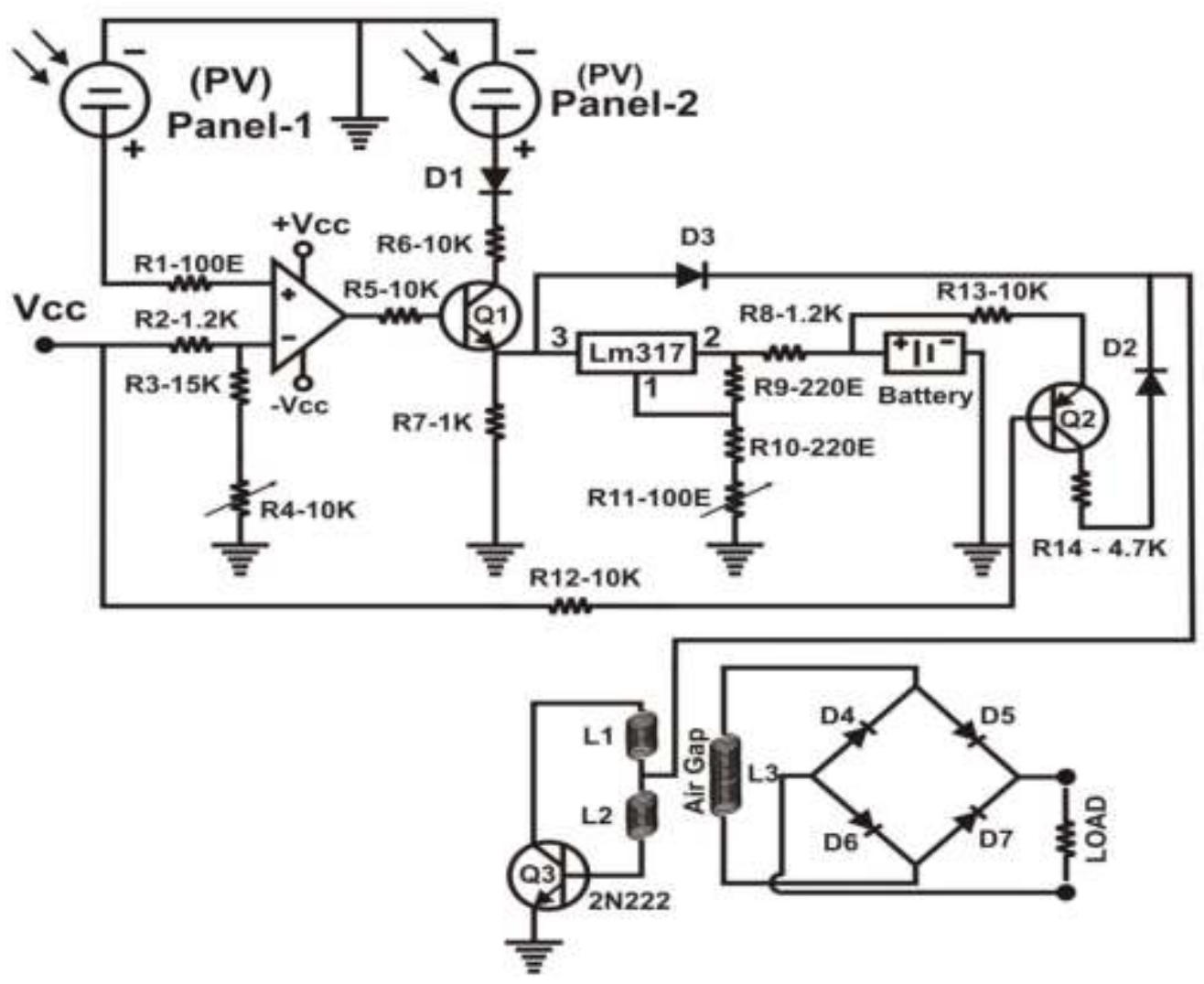

Fig. 3 Circuit diagram of the projected work 
Whereas in Figure 4 with a block diagram, it is shown that, the real time voltage goes to the comparator from solar cell where it is compared with a fixed voltage of the battery. Next when the solar panel voltage is suitable to take, the output of the comparator goes to high and the battery is charged as well as the output signal directly gets transmitted. In next step when efficient solar light is not available then the output of the solar goes to low and the comparator output goes to zero. The circuit gets switched from the solar mode to battery mode and the battery charging process through solar is automatically stopped. In Figure 5 the hardware model of the proposed work is shown with the rectified output in the oscilloscope.

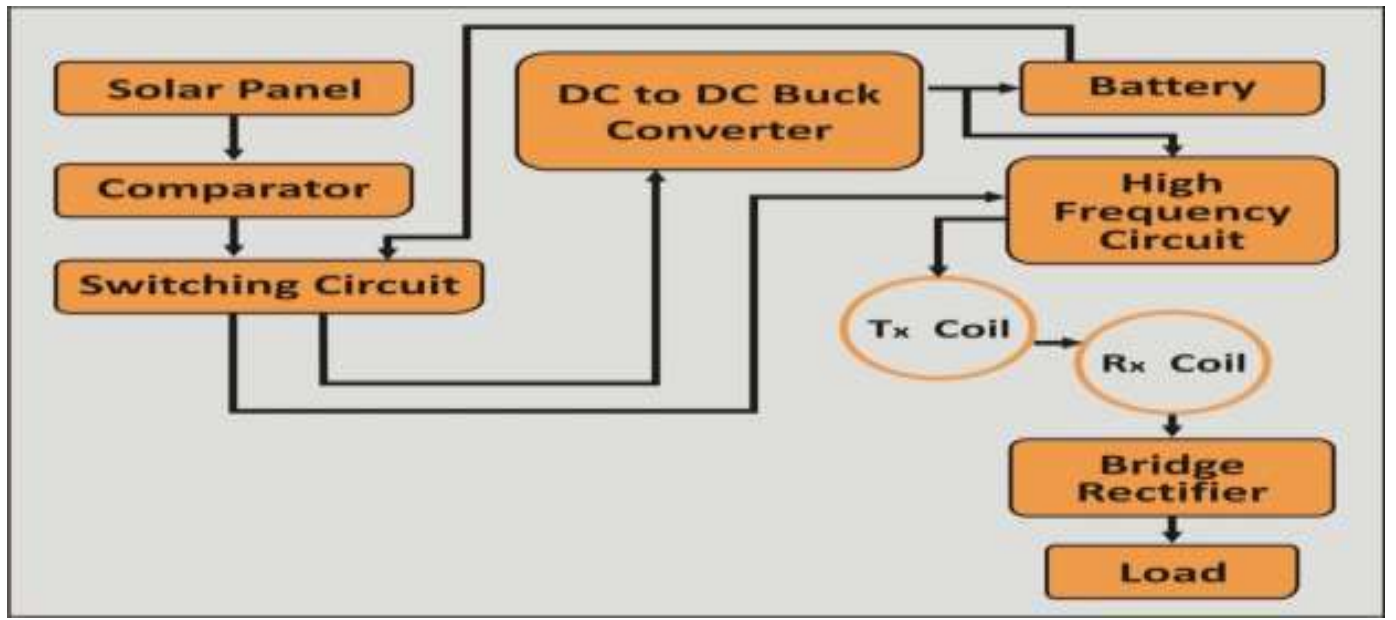

Fig. 4 Block diagram of the proposed system

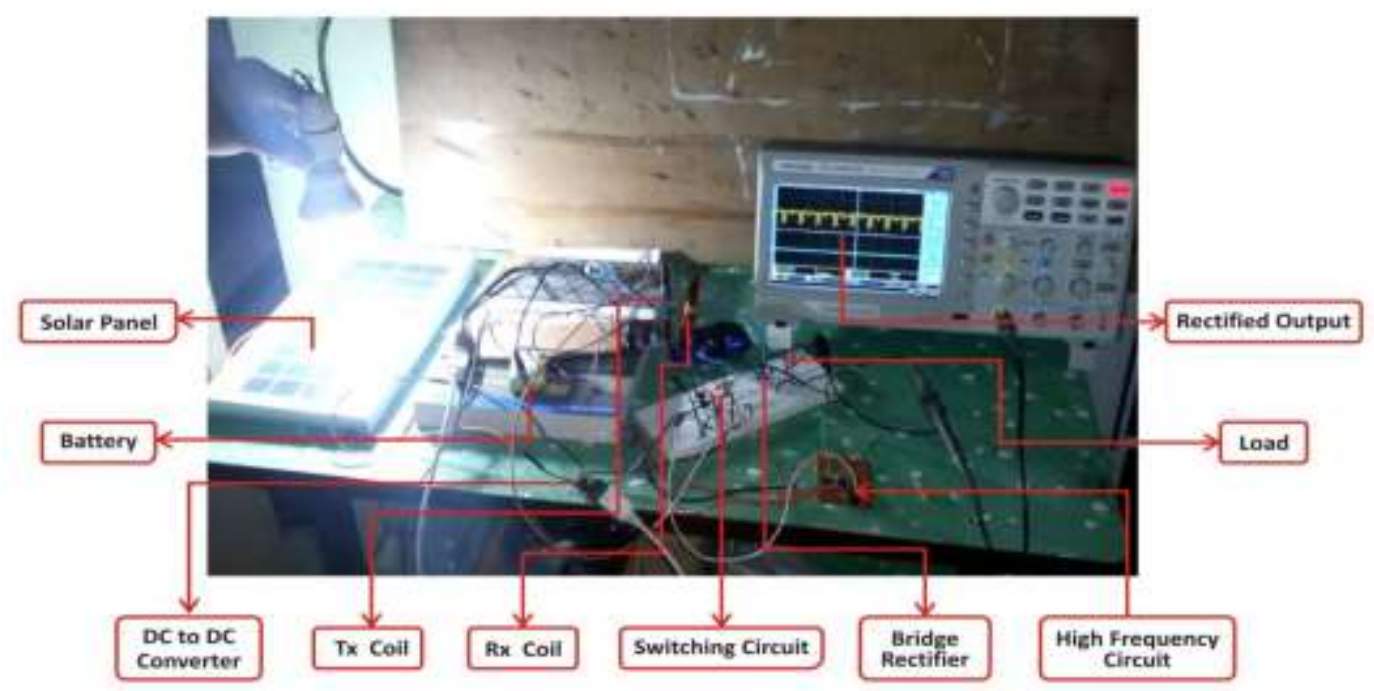

Fig.5 Hardware model of the system

\section{RESULTS AND DISCUSSION}

From Figure 6 it is noticed that initially as the distance increases, the corresponding frequency decreases and as the distance reaches its maximum value at $70 \mathrm{~mm}$ where the applied low voltage DC load stops its functioning, the frequency suddenly starts to increase and reaches its maximum value $2.18 \mathrm{MHz}$. Table I (a) shows the experimental results of distance with frequency limits. 


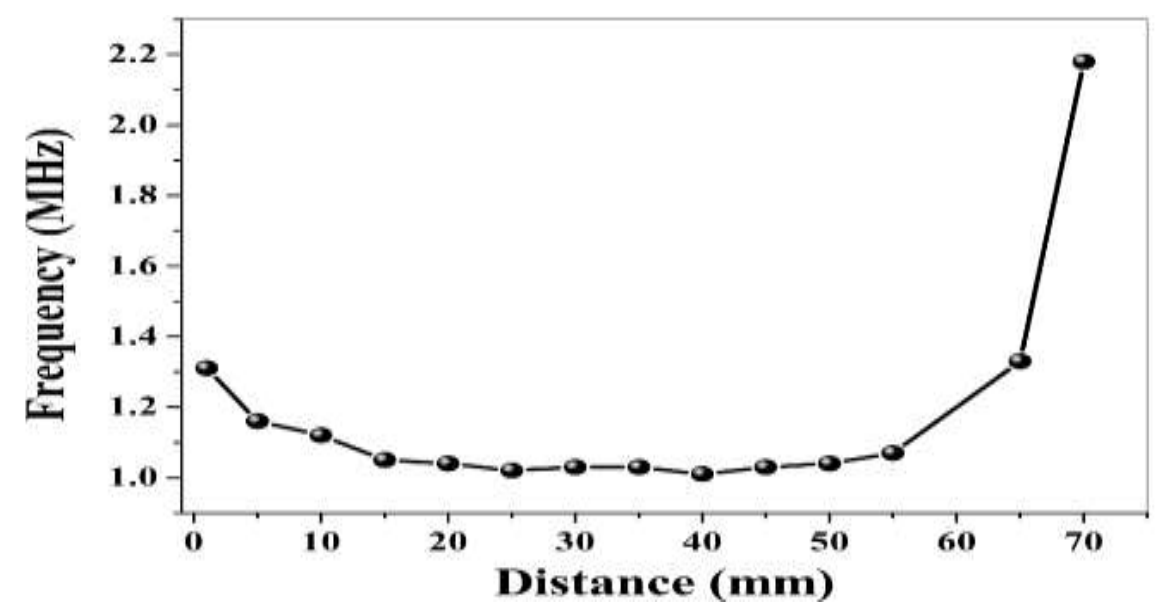

Fig. 6 Distance vs. Frequency variation of the proposed system

Table I. (a). Experimental Data of Distance Vs. Frequency

\begin{tabular}{cc}
\hline Distance $(\mathbf{m m})$ & Frequency $(\mathbf{M H z})$ \\
\hline 1 & 1.31 \\
5 & 1.16 \\
10 & 1.12 \\
15 & 1.05 \\
20 & 1.04 \\
25 & 1.02 \\
30 & 1.03 \\
35 & 1.03 \\
40 & 1.01 \\
45 & 1.03 \\
50 & 1.04 \\
55 & 1.07 \\
60 & 1.03 \\
65 & 1.33 \\
70 & 2.18 \\
\hline
\end{tabular}

In Table I (b) the corresponding statistical analysis of mean and median of distance and frequency represented as 35.06, 1.16 and 35, 1.05 respectively. By studying the correlation coefficient with a calculated value of 0.3634 , it is visible that how the experimental data of distance vs. frequency are correlated with each other.

Table I. (b). Statistical Analysis of Distance vs. Frequency

\begin{tabular}{|c|c|c|c|c|}
\hline Observation & \multicolumn{3}{|c|}{ Analysis of TABLE I (a) } \\
\hline \multirow{7}{*}{15} & \multicolumn{2}{|c|}{ Distance(mm) } & Frequency(MHz) \\
\cline { 2 - 5 } & Mean & 35.06 & Mean & 1.16 \\
\cline { 2 - 4 } & Median & 35 & Median & 1.05 \\
\cline { 2 - 4 } & \multicolumn{2}{|c|}{$\begin{array}{c}\text { Correlation } \\
\text { Coefficient value } \\
\text { between Distance and } \\
\text { Frequency data }\end{array}$} & \multicolumn{2}{|c}{0.3634} \\
\hline
\end{tabular}

In Figure 7 it is detected that as the frequency increases the p-p amplitude of the output signal starts falling down and its behavior shows almost exponentially decaying nature. The experimental data in Table II(a) and with their statistical analysis in Table II(b) 
proves the graphical nature appropriately. By validating the correlation coefficient with a calculated value of -0.2792 , it is visible that how the calculated data of frequency vs. p-p amplitude are associated with each other.

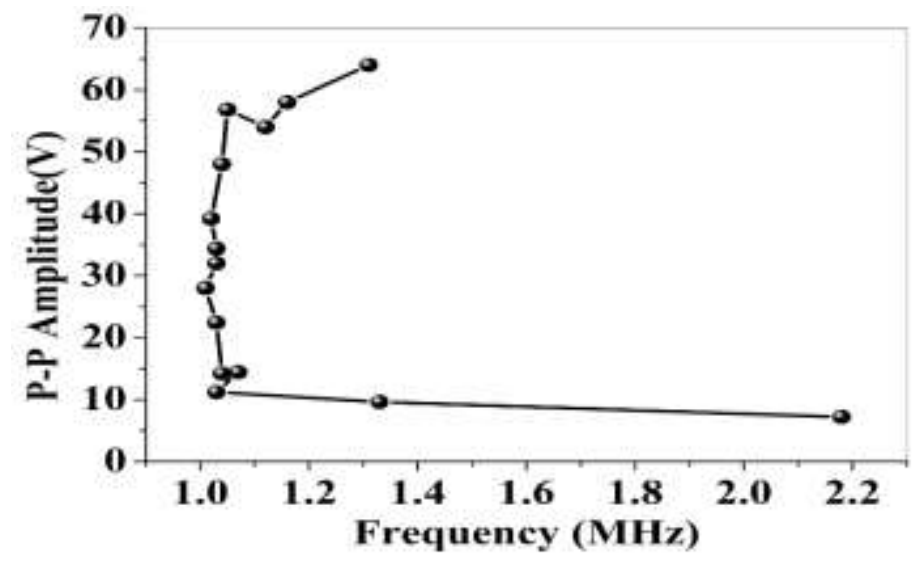

Fig. 7 Frequency vs. P-P Amplitude variation of the proposed WPT

Table II. (a). Experimental Data of Frequency vs. P-P Amplitude

\begin{tabular}{cc}
\hline Frequency(MHz) & P-P Amplitude(V) \\
\hline 1.31 & 64 \\
1.16 & 58 \\
1.12 & 54 \\
1.05 & 56.8 \\
1.04 & 48 \\
1.02 & 39.2 \\
1.03 & 34.4 \\
1.03 & 32 \\
1.01 & 28 \\
1.03 & 22.4 \\
1.04 & 14.2 \\
1.07 & 14.4 \\
1.03 & 11.2 \\
1.33 & 9.6 \\
2.18 & 7.2 \\
\hline
\end{tabular}

Table II (b). Statistical Analysis of Frequency vs. P-P Amplitude

\begin{tabular}{|c|c|c|c|c|}
\hline Observation & \multicolumn{3}{|c|}{ Analysis of TABLE II (a) } \\
\hline \multirow{7}{*}{15} & Frequency(MHz) & \multicolumn{2}{|c|}{ P-P Amplitude(V) } \\
\cline { 2 - 5 } & Mean & 1.16 & Mean & 32.89 \\
\cline { 2 - 4 } & Median & .05 & Median & 32 \\
\cline { 2 - 4 } & $\begin{array}{c}\text { Correlation Coefficient } \\
\text { value between } \\
\text { Frequency vs. P-P } \\
\text { Amplitude data }\end{array}$ & \multicolumn{2}{|c}{-0.2792} \\
\hline
\end{tabular}

From Figure 8 it is noted that when the two coils are adjacent enough, the input power reaches its maximum value but as slowly the distance increases input power starts to falling down .Up to $13 \mathrm{~mm}$ it is found that the input power value is about $6.6 \mathrm{~mW}$ and beyond this limit up to the maximum distance of $70 \mathrm{~mm}$ where the low voltage DC load stops its operation, the input power almost lies in $3.3 \mathrm{~mW}$ constant area which is shown 
in Table III(a) and in Table III(b) with experimental data and their statistical mathematical analysis accordingly. The corresponding experimental data and statistical analysis verifies the limiting nature of the graphical behavior. By verifying the correlation coefficient with a calculated value of -0.6916 , it is visible that how the calculated data of distance vs. input power is linked with each other.

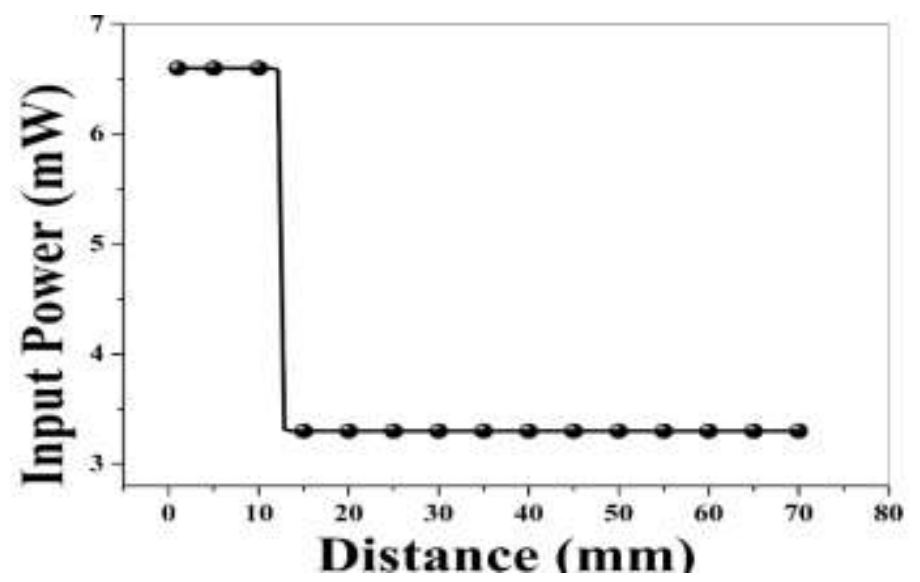

Fig. 8 Distance vs. Input Power of the system

Table III. (a). Experimental Data of Distance vs. Input Power

\begin{tabular}{cc}
\hline Distance $(\mathbf{m m})$ & Input Power $(\mathbf{m W})$ \\
\hline 1 & 6.6 \\
5 & 6.6 \\
10 & 6.6 \\
15 & 3.3 \\
20 & 3.3 \\
25 & 3.3 \\
30 & 3.3 \\
35 & 3.3 \\
40 & 3.3 \\
45 & 3.3 \\
50 & 3.3 \\
55 & 3.3 \\
60 & 3.3 \\
65 & 3.3 \\
70 & 3.3 \\
\hline
\end{tabular}

Table III. (b). Statistical Analysis of Distance vs. Input Power

\begin{tabular}{|c|c|c|c|c|}
\hline Observation & \multicolumn{3}{|c|}{ Analysis of TABLE III (a) } \\
\hline \multirow{7}{*}{15} & \multicolumn{2}{|c|}{ Distance(mm) } & \multicolumn{2}{|c|}{ Input Power(mW) } \\
\cline { 2 - 5 } & Mean & 35.06 & Mean & 3.96 \\
\cline { 2 - 4 } & Median & 35 & Median & 3.3 \\
\cline { 2 - 4 } & $\begin{array}{c}\text { Correlation } \\
\text { Coefficient value } \\
\text { between Distance and } \\
\text { Input Power data }\end{array}$ & \multicolumn{2}{|c|}{-0.6916} \\
\hline
\end{tabular}

From Figure 9, it has been noticed that as the distance increases the output power decreases almost exponentially. The maximum output power has been observed is $128 \mathrm{~mW}$, at a distance of $1 \mathrm{~mm}$. As the distance increases the power decreases gradually. After a distance of $70 \mathrm{~mm}$ the practical applied low voltage DC load which is applied here stops it's working due to the absence of output power. The maximum output power is observed when the distance between the two coils almost comes to zero value. After 
statistical analysis in Table IV (b) of the collected data from the experiment Table IV (a), it is identified that the mean, median values of distance vs. output power are 35.6, 44.60 and 35, 32 accordingly. Whereas the corresponding correlation coefficient between the data of distance and output power is -0.9075 .

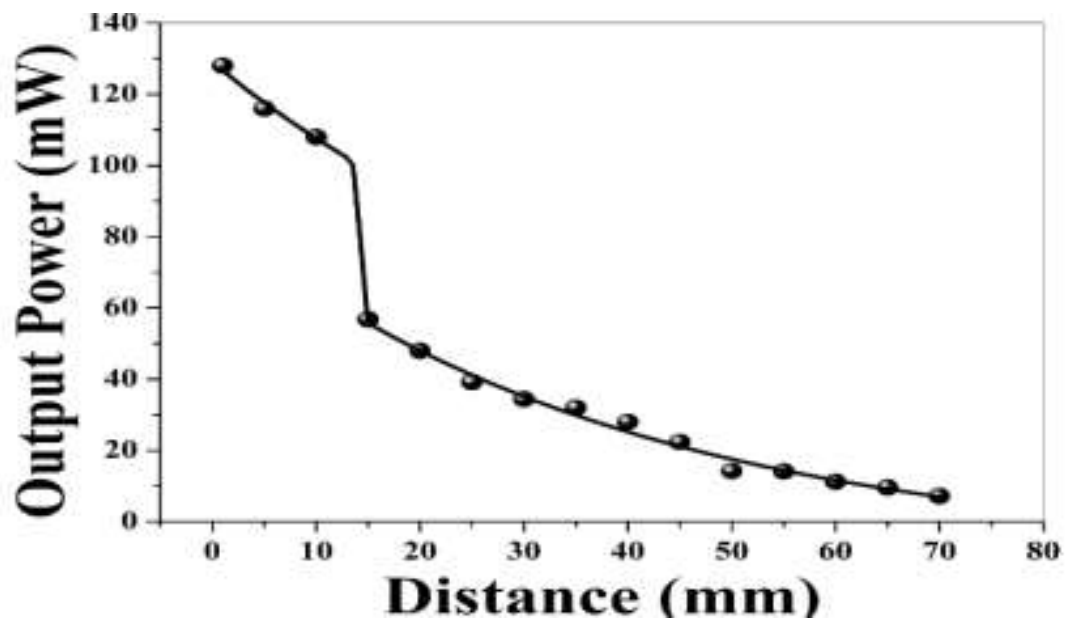

Fig. 9 Distance vs. Output power of the model

Table IV. (a). Experimental Data of Distance vs. Output Power

\begin{tabular}{cc}
\hline Distance(mm) & Output Power $(\mathbf{m W})$ \\
\hline 1 & 128 \\
5 & 116 \\
10 & 108 \\
15 & 56.8 \\
20 & 48 \\
25 & 39.2 \\
30 & 34.4 \\
35 & 32 \\
40 & 28 \\
45 & 22.4 \\
50 & 14.2 \\
55 & 14.1 \\
60 & 11.2 \\
45 & 22.4 \\
65 & 9.6 \\
70 & 7.2 \\
\hline
\end{tabular}

Table IV. (b). Statistical Analysis of Distance vs. Output Power

\begin{tabular}{|c|c|c|c|c|}
\hline Observation & \multicolumn{3}{|c|}{ Analysis of TABLE IV (a) } \\
\hline \multirow{7}{*}{15} & \multicolumn{2}{|c|}{ Distance(mm) } & \multicolumn{2}{c|}{ Output Power(mW) } \\
\cline { 2 - 5 } & Mean & 35.06 & Mean & 44.60 \\
\cline { 2 - 4 } & Median & 35 & Median & 32 \\
\cline { 2 - 4 } & $\begin{array}{c}\text { Correlation } \\
\text { Coefficient } \\
\text { valuebetween } \\
\text { Distance and Output } \\
\text { Power data }\end{array}$ & \multicolumn{2}{|c|}{-0.9075} \\
\hline
\end{tabular}


From Figure 10, it is being observed that as the distance increases the efficiency decreases gradually. The value of maximum efficiency which has been detected here is $19.33 \%$ at a distance of $1 \mathrm{~mm}$ and as the distance increases the efficiency losses gradually. After a distance of $70 \mathrm{~mm}$ the practical applied DC load stops its flashing. The maximum efficiency is observed when the distance between the two coils almost comes to zero value. After a statistical analysis in Table V(b) by the collected data from Table $\mathrm{V}(\mathrm{a})$, it is found that the mean, median values of distance vs. efficiency are $35.06,10.39$ and 35, 9.69 accordingly. Whereas the corresponding correlation coefficient between the data of distance and efficiency is -0.9879 . Key relationship between the four converters has been depicted in Table VI.

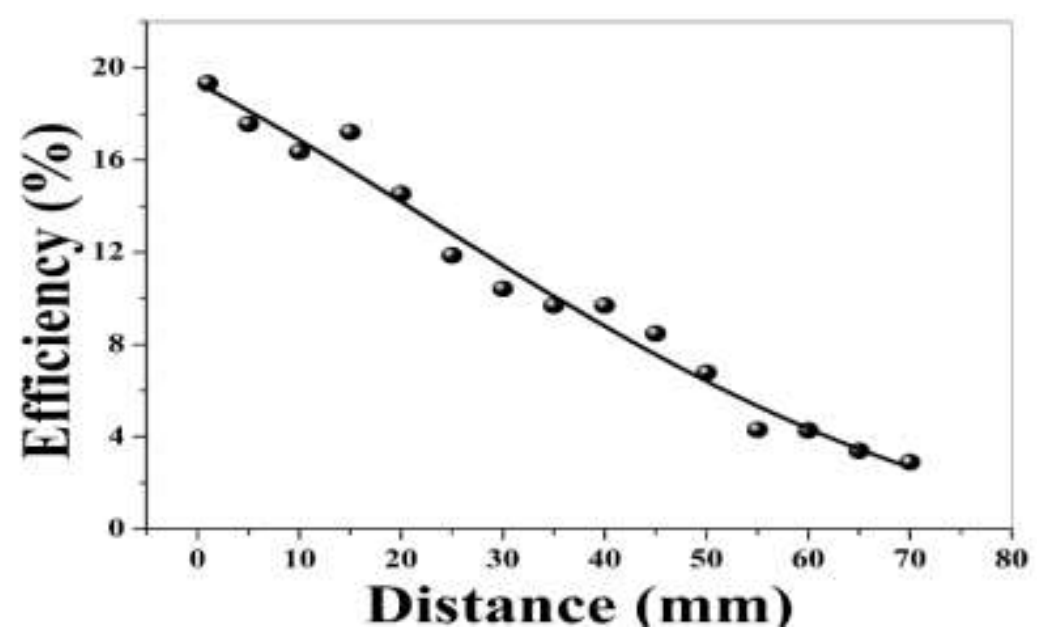

Fig. 10 Distance vs. Efficiency of the system

Table V. (a). Experimental Data of Distance vs. Efficiency

\begin{tabular}{cc}
\hline Distance(mm) & Efficiency (\%) \\
\hline 1 & 19.33 \\
5 & 17.57 \\
10 & 16.36 \\
15 & 17.21 \\
20 & 14.54 \\
25 & 11.87 \\
30 & 10.42 \\
35 & 9.69 \\
40 & 9.69 \\
45 & 8.48 \\
50 & 6.78 \\
55 & 4.30 \\
60 & 4.27 \\
65 & 3.39 \\
70 & 2.90 \\
\hline
\end{tabular}

Table V. (b). Statistical Analysis of the Data of Distance vs. Efficiency

\begin{tabular}{|c|c|c|c|c|}
\hline Observation & \multicolumn{3}{|c|}{ Analysis of TABLE V(a) } \\
\hline \multirow{7}{*}{15} & \multicolumn{2}{|c|}{ Distance(mm) } & \multicolumn{2}{|c|}{ Efficiency (\%) } \\
\cline { 2 - 5 } & Mean & 35.06 & Mean & 10.39 \\
\cline { 2 - 4 } & Median & 35 & Median & 9.69 \\
\cline { 2 - 4 } & $\begin{array}{c}\text { Correlation } \\
\text { Coefficient value } \\
\text { between Distance vs. } \\
\text { efficiency data }\end{array}$ & \multicolumn{2}{|c|}{-0.9879} \\
\hline
\end{tabular}


Table VI. Key Relationship for the Four Compensated Converters Functioning at W

\begin{tabular}{|c|c|c|c|}
\hline SS & SP & PP & PS \\
\hline $\mathrm{C}_{\mathrm{P}-\mathrm{SS}}=1 /\left(\mathrm{w}^{2} \mathrm{~L}_{\mathrm{P}}\right)$ & $\begin{array}{c}\mathrm{C}_{\mathrm{P}-\mathrm{SP}}=\frac{1}{\left[\mathrm{w}^{2} \mathrm{~L}_{\mathrm{P}}\left(1-\mathrm{h}^{2}\right)\right]}, \\
\mathrm{h}^{2}=\frac{\mathrm{M}^{2}}{\mathrm{~L}_{\mathrm{P}} \mathrm{L}_{\mathrm{S}}}\end{array}$ & $\begin{array}{c}\mathrm{C}_{\mathrm{P}-\mathrm{PP}}=\frac{1}{\left[\mathrm{w}^{2} \mathrm{~L}_{\mathrm{P}}\left(1-\mathrm{h}^{2}\right)\right]} \\
\mathrm{h}^{2}=\frac{\mathrm{M}^{2}}{\mathrm{~L}_{\mathrm{P}} \mathrm{L}_{\mathrm{S}}}\end{array}$ & $\begin{array}{l}C_{p-P S} \\
=\frac{1}{\left(w^{2} L_{P}\right)}\end{array}$ \\
\hline $\mathrm{C}_{\mathrm{s}-\mathrm{SS}}=1 /\left(\mathrm{w}^{2} \mathrm{~L}_{\mathrm{s}}\right)$ & $C_{s-S P}=\frac{1}{\left(w^{2} L_{s}\right)}$ & $C_{S-P P}=\frac{1}{\left(w^{2} L_{S}\right)}$ & $\mathrm{C}_{\mathrm{s}-\mathrm{PS}}=\frac{1}{\mathrm{w}^{2} \mathrm{~L}_{\mathrm{s}}}$ \\
\hline- & - & $\mathrm{L}_{\mathrm{i}-\mathrm{PP}}=\mathrm{L}_{\mathrm{P}}\left(1-\mathrm{h}^{2}\right)$ & $\mathrm{L}_{\mathrm{i}-\mathrm{PS}}=\mathrm{L}_{\mathrm{P}}$ \\
\hline$\frac{\mathrm{V}_{\mathrm{L}-\mathrm{SS}}}{\mathrm{V}_{\mathrm{S}}}=-\frac{\mathrm{R}_{\mathrm{L}}}{j w h \sqrt{\mathrm{L}_{\mathrm{P}} \mathrm{L}_{\mathrm{S}}}}$ & $\frac{\mathrm{V}_{\mathrm{L}-\mathrm{SP}}}{\mathrm{V}_{\mathrm{S}}}=\frac{1}{\mathrm{M}} \sqrt{\frac{\mathrm{L}_{\mathrm{S}}}{\mathrm{L}_{\mathrm{P}}}}$ & $\begin{array}{l}\frac{\mathrm{V}_{\mathrm{L}-\mathrm{PP}}}{\mathrm{V}_{\mathrm{S}}} \\
=\frac{\mathrm{h}}{1-\mathrm{h}^{2}} \times \frac{\mathrm{R}_{\mathrm{L}}}{\mathrm{jw} \sqrt{\mathrm{L}_{\mathrm{P}} \mathrm{L}_{\mathrm{S}}}}\end{array}$ & $\frac{\mathrm{V}_{\mathrm{L}-\mathrm{PS}}}{\mathrm{V}_{\mathrm{S}}}=\mathrm{h} \sqrt{\frac{\mathrm{L}_{\mathrm{S}}}{\mathrm{L}_{\mathrm{P}}}}$ \\
\hline
\end{tabular}

\section{CONCLUSION}

A practical and low profile arrangement has been shown with a noble and integrated wireless power transfer system to achieve high power transfer efficiency within a short distance for near field purpose. An equivalent circuit model has been presented here to identify these characteristics. The complete system has been planned and implemented with an input to the circuit of $8.97 \mathrm{~V}, 0.34 \mathrm{~A}$ from the solar PV and a low voltage DC load of $1.2 \mathrm{~V}, 20 \mathrm{~mA}$ has been charged by the circuit. The power efficiency has been accomplished of $19.33 \%$ with a transmission frequency of $2.18 \mathrm{MHz}$ at a distance of $70 \mathrm{~mm}$. From the above described analysis based on wireless power transfer using inductive coupling principle it can be concluded that this projected system is appropriate to be implemented for mobile phone charger, electric vehicles, laptop and other electric and electronic gadgets for the development of a smart society.

\section{REFERENCES}

[1] Alanson P. Sample, David T. Meyer and Joshua R. Smith "Analysis,experimental results and range adaptation on magnetically coupled resonators for wireless power transfer," IEEE Transctions on Industrial Electronics,58.2,(2011): 149-173.

[2] Andre Kurse, Aristeidis Karalis, Robert Moffatt, J. D.Joannopoulos and Marin Soljacic, "Wireless power transfer via strongly coupled magnetic resonance," Science, 317(2007): 83-85.

[3] Hyungrak Kim and Hong-Min Lee, "Design of an integrated wireless power transfer system with high power transfer efficiency and compact structure," $6{ }^{\text {th }}$ European Conference on Antennas and Propagation. (EUCAP), Parague, 26- 30 March 2012, pp. 3627-3630. IEEE Xplore, ieeexplore.ieee.org/document /6206350 / authors\# authors.

[4] Ashwi Kumar Balaji,Trishna Raj, Firoza Patel, and Prashant Kumar Soori, "Intelligent inductive power transfer system for electric vehicles," International Conference on Emerging Technologies and Innovative Business Practices for the transformation of societies, Balaclava, Mauritius,3-6 August 2016,pp.1-4. IEEE Xplore,ieeexplore.ieee.org/document/7737300.

[5] Chwei SenWang, G. A Covic, and O.H. Stielau, "Power transfer capability and bifurcation phenomena of loosely coupled inductive power transfer system," IEEE Transctions on Industrial Electronics,51.1 (2004): 148-157.

[6] Xavier Del Toro Garcia, Javier Vazquaz and Pedro Roncero Sanchez, "Design, implementation issues and performance of an inductive power transfer system for electric vehicle charges with series-series compensation, "IET Power Electronics,8.10(2015): 1920-1930.

[7] Mohamma Ibrahim, Laurent Bernard, Lionel Pichon, Adel Razek, J. Houivet, and O. Cayol, "Advanced modelling of a $2 \mathrm{~kW}$ series series resonating inductive charger for real electrical vehicle," IEEE Transctions on Vechular Technology,64.2 (2015): 421-430.

[8] M. Fareq, M. Fitra, M. Irwanto, H.S. Syafruddin, N. Gomesh, S. Farrah, and M. Rozalian, "Solar wireless power transfer using inductive coupling for mobile phone charger," $8^{\text {th }}$ International Conference on Power engineering and Optimization (PEOCO), Langkawi, Malaysia, 24-25 March 2014, pp.473-476. IEEE Xplore,ieeeexplore.ieee.org/document/6814475.

[9] T. Roith, V.S. Samhitha, and I.Mamatha,"Wireless transmission of solar power using inductive resonant principle," Biennial International Conference on Power and Energy System(PESTSE), Bangalore, India, 21- 23 June 2016,pp.1-6, IEEE Xplore, ieeexplore.ieee.org/document/7516535. 
[10] Adil Salman, Ali Abbas, Javaria. Maqbool and Kamran M. Liaqat Bhatti, "Efficient wireless electric power transmission using magnetic resonance coupling, " Journal of Scientific \& Engineering Research, 5.1 (2014): 2235-2238.

[11] Xun Liu, W. M. Ng, C.K. Lee and S.Y. Hui, "Optimal operation of contactless transformers with resonance in secondary circuits," $23^{\text {rd }}$ Annual Applied Power Electronics Conference and Expositions, Austin , USA, 24-28 February 2008, pp.645-650, IEEE Xplore,ieeexplore.ieee.org/ document/ 4522790.

[12] Dukju Ahn and Songcheol Hong, "A study on magnetic field repeaters in wireless power transfer," IEEE Transactions on Industrial Electronic, 60(2013): 360-371.

[13] Woongso Na, Junho Park, Cheol Lee, Kyoungjun Park, Joongheon Kim and Sungrae Cho, "Energy efficient mobile charging for wireless power transfer in internet of things," IEEE Internet of things Journal,5.1 (2018): 72-92

[14] Uthman Baroudi, "Robot assisted maintenance of wireless sensor networks using wireless energy transfer," IEEE Sensor Journal, 17.14 (2017): 4661-4671.

[15] Liang Jerry Chen, John T Boys and Grant A Covic, "Power management for multiple-pickup IPT systems in materials handling application," IEEE Journal of Emerging and selected topics in Power Electronics, 3.1 (2015): 191-200.

[16] Aaron Qingwei Caj and Liter Siek, "A 2kW 95\% efficiency Inductive power transfer system using Gallium Nitride gate injection transistor," IEEE Journal of Emerging and Selected topics in Power Electronics, 5.1 (2017): 458-468.

[17] Jeijian Dai and Daniel C Ludois, "Capacitive power transfer through a conformal bumper for electric vehicle charging," IEEE Journal of Emerging and selected topics in Power Electronics, 4.3(2016): 10151025.

[18] S. M. Dehghan and M Alinaghizadeh Ardestani, "Solar charger system with LED driver using capacitor less multi-port converter," $7^{\text {th }}$ International Conference on Power Electronics and Drive System (PEDSTC), Tehran, Iran,16-18 February 2016 ,pp.222-227.

[19] Mivkel Budhia,Grant A. Covic and John T. Boys, "Design and optimization of circular magnetic structures for lumped inductive power transfer system, " IEEE Transactions on Power Electronics, 26.11 (2011): 3096-3108.

[20] F. Pellitteri, M. Caruso, V. Castiglia, A.O.D. Tommaso, R. Miceli and L. Schirone, "An Inductive charger for automotive application," $42^{\text {nd }}$ Annual Conference of the IEEE Industrial Electronics Society, (IECON), Florence, Italy,23-26 October 2016, pp.4482-4486.

[21] Konrad Woronowicz, Alireza Safaee and Tim R. Dickson, "Single - phase zero reactive power wireless power transfer topologies based on boucherot bridge circuit concept," Canadian Journal of Electrical and Computer Engineering, 38.4 (2015): 323-337.

[22] Adeel Zaheer, Hao Hao,Grant A.Covic and Dariusz Kacprzak, "Investigation of multiple decoupled coil primary pad topologies in lumped IPT system for interoperable electric vehicle charging," IEEE Transactions on Power Electronics, 30.4 (2015): 1937-1955.

[23] Kafee Ahamed Kalwar, Muhammad Aamir and Saad Mekhilef, "Inductively coupled power transfer (ICPT) for electric vehicle charging-A review," Renewable and Sustainable Energy Reviews, 47.1 (2015): 468-470.

[24] Shih-Ming Chen,Tsorn Juu Liang, Lung Sheng Yang and Jiann.Fuh Chen, "A safety enhanced high step-up DC-DC Converter for AC photovoltaic module application, " IEEE Transactions on Power Electronics, 27.4 (2012): 1809-1817. 
International Journal of Future Generation Communication and Networking Vol. 12, No. 3 (2019) 